\title{
Syncephalastrum racemosum Cohn
}

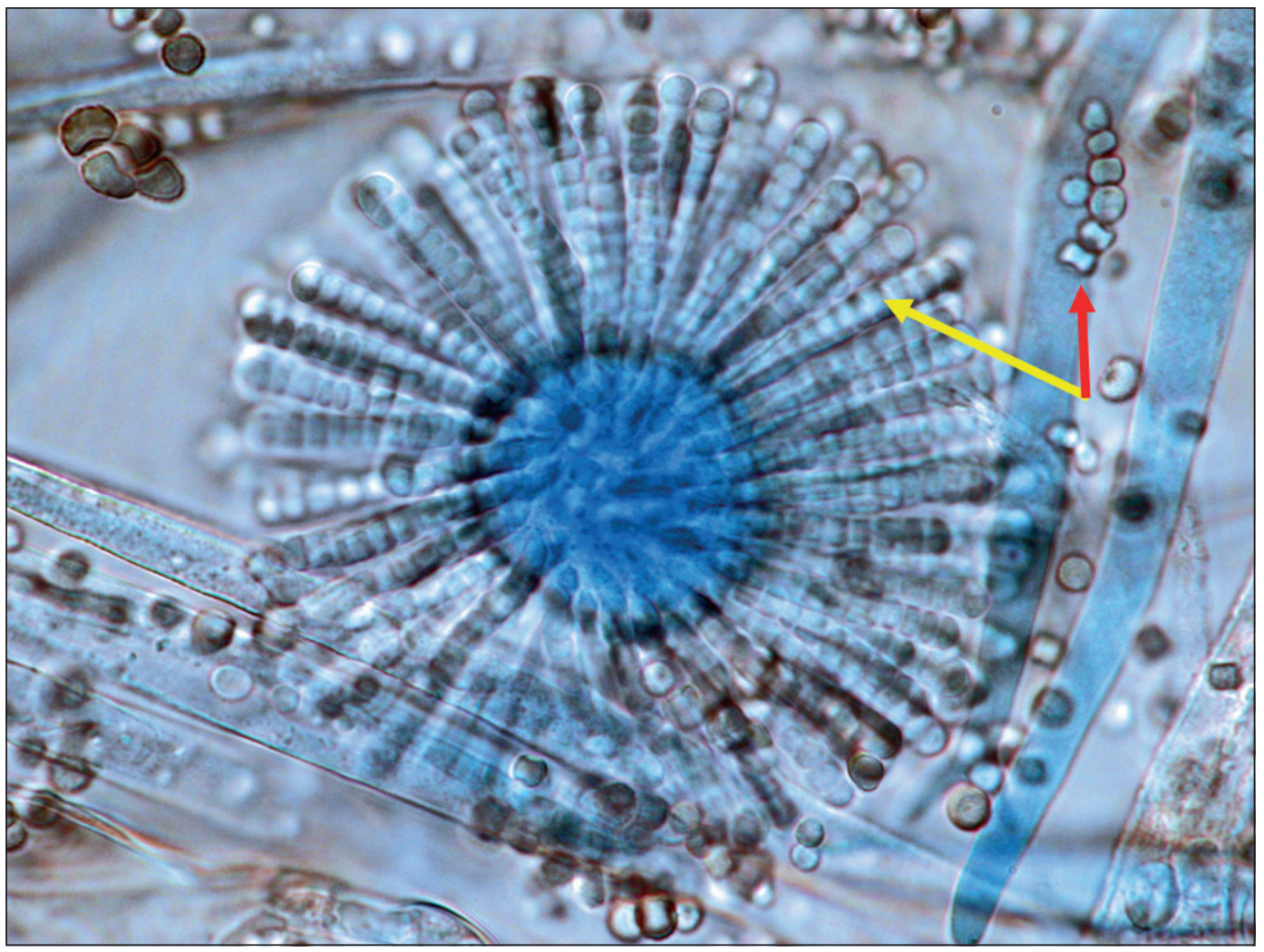

Figura 1. Vesícula con merosporangios y merosporas globosas a ovoides. Tinción de lactofenol con azul de algodón. 40X. 


\section{Syncephalastrum racemosum Cohn}

El género Syncephalastrum está constituido por hongos basales pertenecientes al orden Mucorales. Se encuentra presente en distintos tipos de sustratos orgánicos, preferentemente en el suelo y estiércol de zonas tropicales y subtropicales. Posee una característica distintiva, es el único género que produce merosporangios o esporangios con las esporas dispuestas en una serie lineal (Figura 1), lo cual pudiese llevar eventualmente a confundirlo con el género Aspergillus. Posee potencial patógeno debido a que puede crecer a $37^{\circ} \mathrm{C}$; sin embargo, son pocos los casos de micosis médicas reportadas, relacionándose principalmente con pacientes inmunocomprometidos, uso prolongado de corticoesteroides o diabéticos mal controlados. Se han descrito infecciones de uñas, piel y tejidos blandos, infecciones respiratorias, rinosinusales, del sistema nervioso central o intraabdominales. La identificación correcta y el inicio precoz de la terapia son el pilar de un resultado clínico satisfactorio. Aparte de esto, el grado de inmunocompromiso de los pacientes también ayuda a determinar el pronóstico.

Macroscopía: En agar con extracto de malta (MEA), se observan colonias grises, expandidas y con abundante micelio aéreo.

Microscopía: Esporangióforos que nacen de rizoides, con ramificaciones irregulares, 10-25 $\mu \mathrm{m}$ de ancho, cada rama con una vesícula terminal de hasta $80 \mu \mathrm{m}$ de diámetro, la cual produce merosporangios que cubren la superficie completa, grises, cilíndricos, de hasta $33 \times 4 \mu \mathrm{m}$, de paredes delgadas, evanescentes (flecha amarilla) y conteniendo de 3 a 18 esporangiosporas (merosporas) globosas a ovoides de paredes lisas (Flecha roja). Zigosporas entre suspensores, negras, esféricas, 50-90 $\mu \mathrm{m}$ de diámetro, con proyecciones cónicas.

Fisiología: Temperatura máxima de crecimiento: $40^{\circ} \mathrm{C}$.

Tratamiento de las infecciones: La anfotericina B es el fármaco de elección debido a sus CIM bajas. Como alternativa se puede usar posaconazol. Además, siempre considerar debridamiento quirúrgico en aquellos casos donde sea posible.

\section{Referencias bibliográficas}

1.- Irshad M, Nasir N, Hashmi UH, Farooqi J, Mahmood S F. Invasive pulmonary infection by Syncephalastrum species: Two case reports and review of literature. IDCases 2020; 21: e00913. doi:10.1016/j.idcr.2020.e00913.

2.- Rodríguez-Gutiérrez G, Carrillo-Casas EM, Arenas R, García-Méndez JO, Toussaint S, Moreno-Morales ME. Mucormycosis in a nonHodgkin lymphoma patient caused by Syncephalastrum racemosum: Case report and review of literature. Mycopathologia 2015; 180: 89-93. doi: 10.1007/s11046-015-9878-1.

3.- De Hoog G S, Guarro J, Gené J, Figueras M J. Atlas of Clinical Fungi. Westerdijk Fungal Biodiversity Institute. 2021(versión on line).

Rodrigo Cruz Choappa ${ }^{1}$ y Peggy Vieille ${ }^{1}$ ${ }^{1}$ Laboratorio de Micología, Universidad de Valparaíso.

Correspondencia a:

Rodrigo Cruz Choappa rodrigo.cruz@uv.cl 